\title{
Pharmacokinetics, Safety, and Tolerability of a Medicinal Cannabis Formulation in Patients with Chronic Non-cancer Pain on Long-Term High Dose Opioid Analgesia: A Pilot Study
}

\author{
Yvonne Bonomo (D) - Amanda Norman · Lisa Collins • \\ Helen $\mathrm{O}^{\prime}$ Neill $\cdot$ Peter Galettis · Jane Trinca · Nigel Strauss · \\ Jennifer Martin · David Castle
}

Received: October 12, 2021 / Accepted: November 30, 2021 / Published online: December 18, 2021

(C) The Author(s) 2021

\section{ABSTRACT}

Introduction: This phase I open-label study examined pharmacokinetics, safety, and tolerability of escalating doses of a novel combination cannabinoid medication (1:1 tetrahydrocannabinol $[\mathrm{THC}] /$ cannabidiol $[\mathrm{CBD}]$ ) in patients with chronic non-cancer pain (CNCP) on high dose opioid analgesia.

Methods: Nine people with $\mathrm{CNCP}$ and oral morphine equivalent daily dose of $60 \mathrm{mg}$ or higher were recruited. Blood concentrations of

Supplementary Information The online version contains supplementary material available at https:// doi.org/10.1007/s40122-021-00344-y.

\section{Y. Bonomo ( $\square)$}

Department of Addiction Medicine, St Vincent's

Hospital Melbourne, University of Melbourne, P.O.

Box 2900, Fitzroy, VIC 3065, Australia

e-mail: Yvonne.bonomo@svha.org.au

A. Norman · L. Collins · H. O'Neill

Department of Addiction Medicine, St Vincent's

Hospital Melbourne, P.O. Box 2900, Fitzroy, VIC

3065, Australia

P. Galettis

Clinical Pharmacology Laboratory, Faculty of

Health and Medicine, School of Medicine and Public

Health, University of Newcastle, Callaghan, NSW

2308, Australia

J. Trinca

Barbara Walker Centre for Pain Management, St

Vincent's Hospital Melbourne, P.O. Box 2900,

Fitzroy, VIC 3065, Australia
THC, 11-hydroxytetrahydrocannabinol (OHTHC), 11-nor-9-carboxy-tetrahydrocannabinol (COOH-THC), and CBD were assayed weekly. Concentrations were measured after a single dose of $2.5 \mathrm{mg}$ THC/2.5 mg CBD on day 1 , and daily escalating doses up to a single dose of $12.5 \mathrm{mg}$ THC/12.5 mg CBD on day 29. Followup was on day 36 after a 7-day washout. Secondary outcome data encompassed pain, mood, and sleep parameters.

Results: The parent compounds THC, and $\mathrm{CBD}$, and metabolites $\mathrm{OH}-\mathrm{THC}$ and $\mathrm{COOH}-$ THC were detected at most time points. In general, the concentration of all analytes increased until $2 \mathrm{~h}$ post-administration,

\section{N. Strauss}

Millswyn Clinic, 466 Punt Road, South Yarra, VIC

3141, Australia

\section{J. Martin}

School of Medicine and Public Health, Faculty of Health and Medicine, University of Newcastle, Callaghan, NSW 2308, Australia

D. Castle

Mental Health, St Vincent's Hospital Melbourne, University of Melbourne, P.O. Box 2900, Fitzroy, VIC 3065, Australia 
decreasing to approximately pre-dose concentrations by $8 \mathrm{~h}$. There was considerable interand intra-individual variability. The study medication was well tolerated. Eight participants reported at least one adverse event (AE), with a total of 62 AEs; most common were euphoric mood, headache, and agitation, none classified as severe. There was no significant change to pain severity self-ratings, nor use of pain medications. Improvements in pain interference scores, mood, and some sleep parameters were observed.

Conclusion: The THC/CBD formulation was tolerated well in a group of patients with CNCP. Between-participant variability supports personalized dosing and "start low-go slow" titration. To validate and quantify improvements in secondary efficacy outcomes a randomized placebo-controlled study is needed.

Trial Registration: Australian New Zealand Clinical Trials Register (CT-2019-CTN-01224-1).

\section{PLAIN LANGUAGE SUMMARY}

Many studies use healthy volunteers when they look at the way medicines are absorbed in the body and their clinical effects. The aim of this project was to examine a new formulation of medicinal cannabis in people who have chronic pain and other health conditions to help us to plan a larger study. We wanted information on how quickly it was absorbed and whether there were any negative effects of the medicine. We wondered whether the fact that participants were on a number of other medications might mean that we see different results to those seen with healthy volunteers. We found that the results of our group were very similar to those seen in other studies. Although we only tested a small number of participants we did not observe serious negative effects of the medication, and saw some positive effects on mood and sleep. We now have the data to assist us in planning a larger study which should provide important guidance to prescribers of medicinal cannabis in the future.
Keywords: Medicinal cannabis; THC; CBD; Pharmacokinetics; Safety; Chronic pain

\section{Key Summary Points}

This study investigated pharmacokinetics of a novel cannabinoid formulation in participants with chronic non-cancer pain and on high dose opioid medication.

Considerable inter- and intra-individual variability was observed, which is important for clinicians to be aware of when caring for patients on these treatments.

This study provides important pilot data to inform a subsequent randomized controlled trial.

\section{INTRODUCTION}

Delta-9-tetrahydrocannabinol (THC) and cannabidiol (CBD) are the principal active constituents of cannabis. THC is the main psychoactive constituent of cannabis, its pharmacological effects including analgesia, muscle relaxation, antiemesis, and appetite stimulation [1]. CBD is the main non-intoxicating phytocannabinoid present in the Cannabis sativa plant, constituting up to $40 \%$ of its extract [2]. CBD has demonstrated a broad spectrum of potential therapeutic properties in animal models and humans, including anxiolytic [2, 3], antidepressant [4], neuroprotective [2, 5], antiinflammatory and immunomodulatory [6] actions.

There is evidence that the combination of THC and CBD increases clinical efficacy while reducing adverse events [7]. This makes pharmacological sense as CBD is a strong P450 enzyme inhibitor enabling higher concentrations, and both molecules have a number of receptor interactions depending on concentration. CBD has been demonstrated to ameliorate some undesirable effects of THC including intoxication, sedation, and tachycardia, while 
contributing analgesic, and antiemetic, properties [7]. There are some reports that cannabinoids may enable patients to reduce their opioid medication whilst maintaining adequate analgesia-known as opioid sparing $[8,9]$.

Lynch and Clark [9] published a report of three patients with non-cancer pain stating that regular use of smoked cannabis enabled them to reduce their opioid dose by $60-100 \%$. Other studies have had mixed results: Johnson et al. [10] showed that Sativex ${ }^{\circledR}$, a THC/CBD formulation in an oro-mucosal spray $(2.7 \mathrm{mg} \mathrm{THC} /$ $2.5 \mathrm{mg} \mathrm{CBD}$ ), was more effective than THC only $(2.7 \mathrm{mg})$, and placebo, in moderate to severe cancer-related pain. In this 2-week doubleblind, randomized, placebo-controlled, parallel group trial, no change in the median amount of opioid breakthrough medication was observed in either group. Further, Fallon et al. [11] found no significant effect on pain scores and a nonsignificant opioid-sparing effect in two placebocontrolled randomized controlled trials (RCTs) of Sativex ${ }^{\circledR}$ in patients with advanced cancer pain. Lichtman et al. [12] in a double-blind, placebo-controlled RCT of patients with advanced cancer found no significant impact of Sativex ${ }^{\circledR}$ on average pain score or daily maintenance opioid dose, breakthrough opioid dose, or total daily opioid dose compared to placebo. However, cancer-related pain has a different pathophysiology to chronic non-cancer pain (CNCP). Seeling et al. [13] examined the use of dronabinol (5 $\mathrm{mg}$ THC) versus placebo in acute post-surgical pain. Median dose of micro-opioid agonist piritramide in the 2 days post-surgery was numerically but not statistically different.

Systematic reviews $[14,15]$ have found some evidence to support an analgesic effect in neuropathic pain. However, the quality of evidence to support the analgesic and opioid-sparing effect of cannabinoids for CNCP and cancer pain is low because of a lack of high-quality RCTs, the heterogeneous nature of the populations studied, and the many different formulations of cannabinoids used [16-18].

$\mathrm{CNCP}$ remains one of the most common reasons for use of medicinal cannabinoids; however, there remain a number of unanswered questions regarding their use in this patient group. There is a known inter-individual variability, implying that for many patients the doses chosen for the studies are critical. Further, the choice of cannabinoid, the dosage, and mode of delivery in clinical trials of CNCP conditions have varied widely. For example, THC/CBD extracts have typically been administered as either standardized capsules or as a sublingual spray. In a recent review of randomized clinical trials for treatment of $\mathrm{CNCP}$, total daily dose ranged from $2.5 \mathrm{mg}$ THC/ $2.5 \mathrm{mg}$ CBD to $97.5 \mathrm{mg} \mathrm{THC} / 97.5 \mathrm{mg} \mathrm{CBD}$, similarly for neuropathic pain [19].

This pilot study was designed to guide and inform a proposed subsequent RCT which will address some of the knowledge gaps regarding analgesic properties and opioid-sparing effects of cannabinoids. The primary objectives of this study were to assess the pharmacokinetics of a novel THC/CBD formulation following a single oral dose and following repeated escalating oral doses; to assess the impact of a high fat diet (HFD) on THC/CBD absorption; and to evaluate the safety and tolerability of the novel THC/ CBD formulation following a single oral dose and following repeated escalating oral dosing in patients with CNCP.

Secondary objectives were to monitor effects on pain, mood, sleep, and opioid and non-opioid analgesic use over the duration of the trial.

\section{METHOD}

\section{Investigational Product}

The investigational product (ZTL-103) was a formulation of $10 \mathrm{mg}$ THC/10 mg CBD per ml oral solution. The product was manufactured under supervision of the trial sponsor by Replek Farm, Macedonia in accordance with Good Manufacturing Practice (GMP), International Council for Harmonisation-GMP (ICH-GCP), and local regulatory requirements. The product was packaged into ready-to-use pre-filled syringes by Suda Pharmaceuticals (Australia), under GMP conditions. 


\section{Compliance with Ethics Guidelines}

The study protocol, Patient Information and Consent Form (PICF), and Investigator Brochure were approved by the relevant institutional Human Research Ethics Committee (HREC 064/19) for both study sites. The study was conducted in accordance with the Helsinki Declaration of 1994 and subsequent amendments. The trial was prospectively registered with the Australian New Zealand Clinical Trials Register (CT-2019-CTN-01224-1).

\section{Study Population}

Eligible participants were aged over 25 years with $\mathrm{CNCP}$, on long-term treatment (at least 12 months) with high dose (oral morphine equivalent daily dose [OMEDD] $\geq 60 \mathrm{mg}$ ) opioid analgesia. Participation was voluntary under conditions of informed consent.

Participants were recruited at two sites, a public hospital pain management clinic and at a community medicinal cannabis clinic. Eligibility screening, informed consent, and baseline assessment were conducted by a member of the research team.

\section{Eligibility Criteria}

Inclusions: aged over 25 years of age; patients with CNCP on long-term treatment (at least 12 months) receiving high dose (OMEDD > $60 \mathrm{mg}$ ) opioid analgesia; willing to cease driving a motor vehicle for the duration of the study; willing to undertake fasting requirements and meal restrictions whilst providing blood samples for pharmacokinetic studies; agree to undergo all assessments for trial duration of 5 weeks including blood testing for pharmacokinetic analysis; psychometrics and a saliva swab for a drug screen; no cannabis use in previous month, as confirmed by a negative drug screen.

Exclusions: dependence on cannabis; cardiovascular disorder, epilepsy; psychosis, bipolar disorder; first-degree relative with psychosis; dependence on alcohol, benzodiazepines, or amphetamine-type stimulants; women who were pregnant, lactating, or not using adequate contraception; men who were not using adequate contraception; evidence of severe hepatic/renal impairment; participating in another clinical trial; active malignancy; inability to self-administer the cannabinoid formulation with the graduated pre-filled syringe.

\section{Limitations Regarding Prior and Concomitant Treatments/Drug Interactions}

Pharmacokinetic studies are typically conducted in healthy controls. Persons with CNCP often have multiple physical comorbidities and are prescribed multiple medications. This study was conducted in a "real world" cohort which necessitated decisions regarding limitations on prior and concomitant treatments and/or drug interactions.

THC induces CYP1A2 activity and reduces serum concentrations of drugs metabolized by CYP1A2, e.g. anti-psychotic medications such as clozapine, olanzapine, haloperidol, and chlorpromazine [20]. Thus persons with psychosis were excluded from this study. Serum concentrations of duloxetine and naproxen may be reduced with concomitant use of THC: persons on these drugs were eligible for recruitment but were required to be monitored for drug interactions.

As CBD is a potent inhibitor of cytochrome $\mathrm{P}(\mathrm{CYP}) 2 \mathrm{D} 6$ and CYP3A4, there is a potential risk of interaction with other drugs metabolized primarily through these pathways. Tramadol metabolism is primarily mediated through CYP2D6, CYP3A4, and CYP2B6 [21]. Carbamazepine is a potent inducer of CYP3A4, and CBD may inhibit its metabolism resulting in increased serum concentrations. Serum concentrations of topiramate have also been observed to rise with increasing CBD dose but changes have been reported to be within the accepted therapeutic range [22]. The concomitant use of tramadol, carbamazepine, and topiramate were permitted, with those on tramadol or carbamazepine monitored closely for signs of excessive sedation. Current use of valproate was an exclusion for the current study as this 
combination may elevate aspartate transaminase (AST) and/or alanine aminotransferase (ALT) concentrations [23]. Benzodiazepines were excluded because of potential excessive sedation in combination with the investigational product (ZTL-103).

No new medication other than the investigational product, opioid medications for $\mathrm{CNCP}$, and contraceptives was permitted to be commenced after initiation on to the trial.

\section{Overall Study Design}

This was an open-label non-controlled doseescalation study $(n=9)$.

The pharmacokinetics were investigated on day 1 after a single dose of $2.5 \mathrm{mg}$ THC/2.5 mg CBD after fasting for $12 \mathrm{~h}$, day 8 after a single dose of $2.5 \mathrm{mg}$ THC/2.5 mg CBD following a high fat meal, day 15 after a single dose of $5 \mathrm{mg}$ THC/5 mg CBD after twice daily $2.5 \mathrm{mg}$ THC/ $2.5 \mathrm{mg}$ CBD for 7 days, day 22 after a single dose of $7.5 \mathrm{mg}$ THC/7.5 mg CBD after twice daily $5 \mathrm{mg}$ THC/5 mg CBD for 7 days, and day 29 after a single dose of $12.5 \mathrm{mg}$ THC/12.5 mg CBD after twice daily $7.5 \mathrm{mg}$ THC/7.5 mg CBD for 7 days. Participants returned for final assessments on day 36, after a 7-day washout period; however, no bloods were taken on this day as it was not anticipated that there would be any THC or CBD 1 week after a single dose of $12.5 \mathrm{mg}$ THC/12.5 mg CBD. As an indication of this a single dose of $12.5 \mathrm{mg}$ THC/12.5 $\mathrm{mg}$ CBD was given the previous evening at $4 \mathrm{pm}$ prior to the day 29 pharmacokinetic (PK) analysis. The concentrations of THC and CBD in the predose sample approximately $20 \mathrm{~h}$ later were generally around $0.5 \mathrm{ng} / \mathrm{mL}$, the limit of quantitation of our assay. Thus it would be highly unlikely that after a single dose of $12.5 \mathrm{mg}$ THC/12.5 $\mathrm{mg}$ CBD there would be detectable THC and CBD $148 \mathrm{~h}$ later.

To explore secondary objectives, participants completed the Brief Pain Inventory (BPI) [24] which has two subscales, namely pain severity and pain interference (i.e. how pain impacts function and daily life), and recorded opioids, other analgesics, and any other medications, daily. At each visit to the study site (days 1, 8,
$15,22,29,36)$ participants completed the Depression, Anxiety, and Stress Scale (DASS-21) [25], Insomnia Severity Index (ISI) [26], and underwent a physical examination by a clinician. They were also asked about any adverse events related to the study or the study medication.

All participants completed a daily sleep diary. Three variables were recorded: Sleep onset latency (SOL) - the participant's perceived ease of falling asleep (Likert scale); Total sleep time (TST)_- "Last night I slept a total of $x$ hours"; Sleep quality- "When I woke up for the day I felt: refreshed, somewhat refreshed or fatigued".

\section{Pharmacokinetic Sampling}

Four millilitre ethylenediaminetetraacetic acid (EDTA) blood samples were taken for assessment of plasma concentrations of the investigational product (IP) ZTL-103 at pre-dose (time 0 ), $30 \mathrm{~min}, 1 \mathrm{~h}, 2 \mathrm{~h}, 4 \mathrm{~h}$, and $8 \mathrm{~h}$ posttreatment. Bloods were refrigerated at $4{ }^{\circ} \mathrm{C}$ or below, and centrifuged at $2000 \times g$ for $10 \mathrm{~min}$ within $12 \mathrm{~h}$ after sampling. Immediately after centrifugation, plasma was stored in two labelled polypropylene tubes and stored at $-20^{\circ} \mathrm{C}$ or below for plasma concentration analysis. All plasma concentration analyses were performed after all participants had completed the final visit.

Participants were required to fast for $12 \mathrm{~h}$ prior to providing blood samples for PK analysis. On days 1, 15, 22, and 29 participants were offered decaffeinated beverages and digestive biscuits from $15 \mathrm{~min}$ post-dosing. They were provided with lunch at $4 \mathrm{~h}$ post-dose and a light meal late afternoon. On day 8, participants were provided with a high fat breakfast prior to dosing. The breakfast was consistent with the US Food and Drug Administration guidelines for fat and calorific content [27], providing an energy value of approximately $3760 \mathrm{~kJ}(900 \mathrm{kcal})$ and containing approximately $60 \mathrm{~g}$ of fat.

\section{Statistical Analyses}

Statistical analysis using paired $t$ tests was conducted using STATA Version 15.1 and GraphPad 
Prism Version 8.4.3. All participants who received at least one dose of study medication were included in the data analysis. Unless otherwise stated, missing and incomplete data remained with no values, rather than values imputed from a mathematical model.

\section{Analysis of Plasma Samples}

Plasma samples were analysed using a validated LCMSMS (liquid chromatography-tandem mass spectrometry) method for THC, CBD, and the metabolites 11-hydroxytetrahydrocannabinol (OH-THC) and 11-carboxytetrahydrocannabinol (COOH-THC) [28]. Plasma samples were prepared by adding twice the volume of acetonitrile containing deuterated internal standards. The samples were vortexed then centrifuged and the supernatant was transferred to a vial and injected onto the LCMSMS column. The LCMSMS system consisted of a Shimadzu 8060 LCMS using a Kinetex Biphenyl column and a gradient of $0.1 \%$ formic acid and acetonitrile. THC and its metabolites were linear over the following ranges: THC $0.5-500 \mathrm{ng} /$ $\mathrm{mL}$; OH-THC $\quad 0.5-50 \mathrm{ng} / \mathrm{mL}$; COOH-THC $0.5-500 \mathrm{ng} / \mathrm{mL}$; CBD $0.5-500 \mathrm{ng} / \mathrm{mL}$. The limit of quantitation for all compounds was $0.5 \mathrm{ng} /$ $\mathrm{mL}$. Intra-assay precision was between $3 \%$ and $12 \%$ and intra-assay bias was between $-15 \%$ and $12 \%$. Inter-assay precision was between $5 \%$ and $15 \%$ and inter-assay bias was between - $6 \%$ and $15 \%$.

\section{Study Parameters}

Pharmacokinetics: maximum plasma concentration $\left(C_{\max }\right)$, time of $C_{\max }\left(T_{\max }\right)$, area under the plasma concentration time curve $\left(\mathrm{AUC}_{0-8}\right)$, and plasma half-life $\left(t_{1 / 2}\right)$ were determined using PKSolver [29]. The data was fitted using the non-compartmental analysis (NCA) extravascular module, with $\mathrm{AUC}_{0-\mathrm{t}}$ calculated using the log-linear trapezoidal method.

Safety parameters: number and frequency of adverse events (AE) and serious adverse events (SAE) classified using Medical Dictionary for Regulatory Activities (MedDRA); local tolerability; physical examination performed at all visits including the following: vital signs, general appearance, HEENT (head, ears, eyes, nose, and throat), skin, cardiovascular system, respiratory system, gastrointestinal system, nervous system, and other.

Effect parameters: BPI [24]; DASS-21 [25]; ISI [26] (the seven-item ISI plus two additional questions: "How would you rate your sleep quality in the last week?" and "How many hours sleep have you had for the past week?"); Selfreported opioid and pain medication use-at each visit participants were asked to report all medications used including analgesia. There was no instruction for participants to try to reduce their analgesia.

\section{RESULTS}

\section{Participants}

Nine participants were recruited into the study, two at the public hospital and seven at the community clinic. Table 1 describes participant characteristics at baseline.

Participants were predominantly male (7/9). Mean age was 58.1 years (standard deviation $[\mathrm{SD}]=6.2$ ). Mean OMEDD was $92.7 \mathrm{mg}$ per day (range $60-160 \mathrm{mg}$ ). Participants had a range of physical comorbidities and polypharmacy. Six participants reported past cannabis use and one participant reported current cannabis use (in the last 3 months). All participants reported no cannabis use in the last month and returned negative urine drug screens for cannabis. Four participants reported current benzodiazepine use: three ceased use prior to study medication commencement, and one required further instruction at day 8 regarding the need to cease use of benzodiazepines during the trial.

Of the nine participants enrolled, seven (77.8\%) completed the trial and two (22.2\%) discontinued before completion. One was deemed lost to follow-up at day 22 after failing to attend day 29 visit and the other discontinued study medication on day 13 because of post-traumatic stress disorder (PTSD)-related symptoms (participant was discontinued from the study at their day 15 visit). 
Table 1 Summary of participant characteristics at baseline

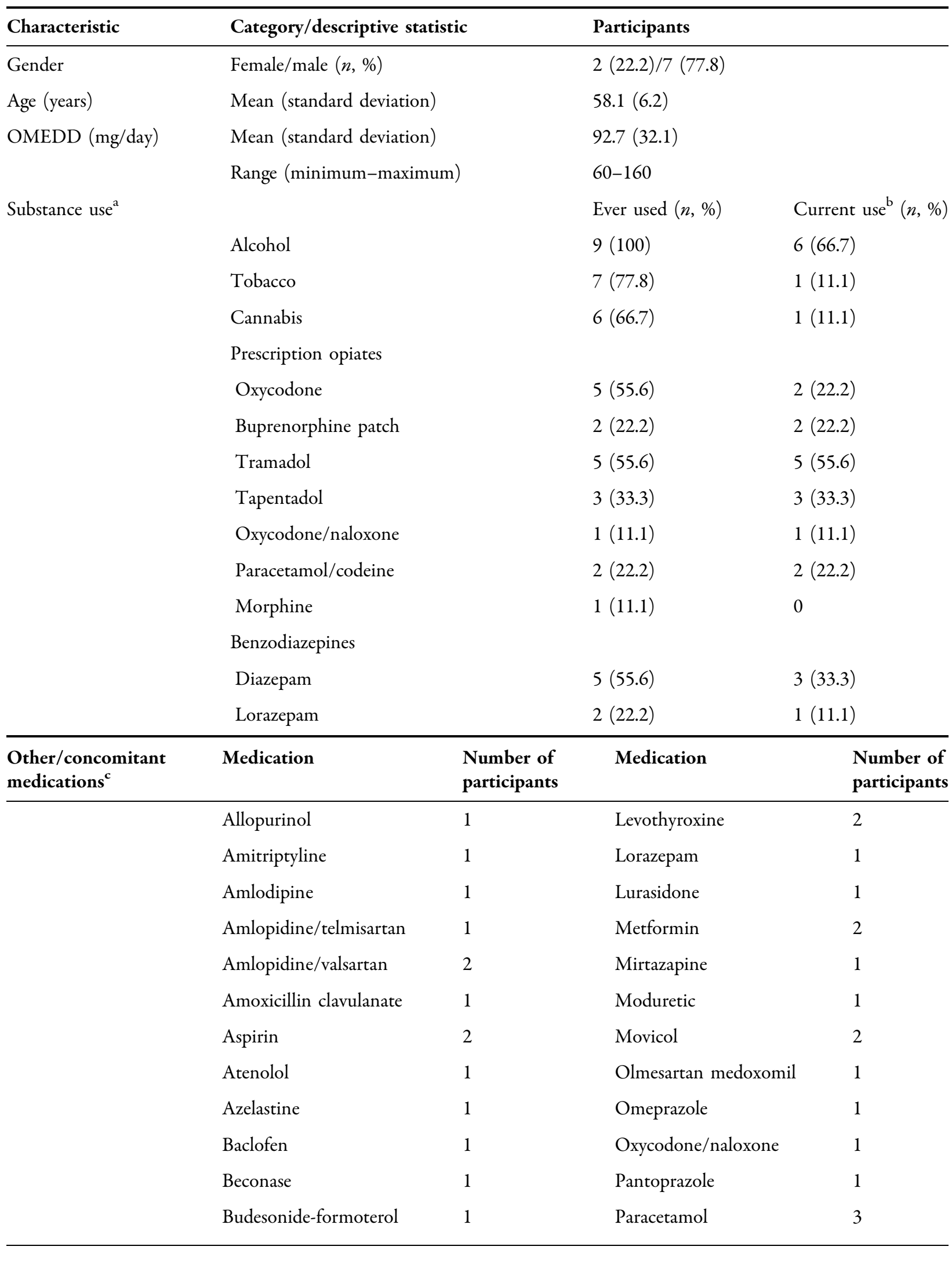


Table 1 continued

\begin{tabular}{lllll}
\hline $\begin{array}{l}\text { Other/concomitant } \\
\text { medications }{ }^{\mathbf{c}}\end{array}$ & Medication & $\begin{array}{l}\text { Number of } \\
\text { participants }\end{array}$ & Medication & $\begin{array}{l}\text { Number of } \\
\text { participants }\end{array}$ \\
\hline Ciprofloxacin & 1 & Perindopril & 2 \\
Clonidine & 2 & Prazosin & 1 \\
Cortisone injection & 1 & Pregabalin & 5 \\
Cyproheptadine & 1 & Probenecid & 1 \\
Desvenlafaxine & 1 & Pseudoephedrine & 1 \\
Diazepam & 1 & Rosuvastatin & 2 \\
Domperidone & 1 & Salbuterol & 1 \\
& Duloxetine & 5 & Seretide & 1 \\
Esomeprazole & 3 & Sertraline & 1 \\
Estrogen & 1 & Sildenafil & 1 \\
Exenatide & 1 & Testosterone & 1 \\
Ezetimibe/simvastatin & 1 & Tiotropium & 1 \\
Fenofibrate & 1 & Valsartan & 1 \\
Gliclazide & 1 & Vitamin D & 1 \\
Indapamide & 1 & &
\end{tabular}

$O M E D D$ oral morphine equivalent daily dose

${ }^{a}$ Multiple prescribed and non-prescribed substances

${ }^{\mathrm{b}}$ Current use refers to substance use within the 3 months prior to baseline. Note, the one participant reporting current cannabis use stated no cannabis use in the last month. This participant, along with five other participants reporting 'ever used' cannabis, all returned negative urine drug screens for cannabis at baseline

${ }^{c}$ Medications used whilst on the trial. Multiple medications for each participant

\section{Pharmacokinetic Study}

The mean concentration time data for all subjects is shown in Fig. 1. There was no detection of any analytes before treatment at the $2.5 \mathrm{mg}$ dose on day 1 or day 8 . Measurable concentrations of the COOH-THC metabolite were detectable in all subjects, in the pre-administration of ZTL-103 sample on days 15, 22, and 29.

In general the concentration of $\mathrm{THC}, \mathrm{OH}-$ THC, COOH-THC, and CBD increased until $2 \mathrm{~h}$ after the administration of ZTL-103 and then started to decline. There was also an increase in the concentration of each analyte with increasing dose of ZTL-103.
Pharmacokinetic parameters: Pharmacokinetic data is summarised in Table 2. There was significant inter-subject variability in all the parameters ranging between $30 \%$ and $80 \%$. The $C_{\max }$ was quite low for THC $(0.83 \mathrm{ng} / \mathrm{mL})$ and CBD $(0.62 \mathrm{ng} / \mathrm{mL})$ at the $2.5 \mathrm{mg}$ dose of ZTL103 , with values only just above the limit of quantitation. The $C_{\max }$ of the metabolites $\mathrm{OH}$ THC (1.80 ng/mL) and COOH-THC (9.49 ng/ $\mathrm{mL}$ ) was higher than the parent THC at the $2.5 \mathrm{mg}$ dose of ZTL-103. The $T_{\max }$ for all analytes was generally around $2 \mathrm{~h}$. At the $2.5 \mathrm{mg}$ dose of ZTL-103 the $\mathrm{AUC}_{0-8}$ for THC was $2 \mathrm{ng} /$ $\mathrm{mL} \times \mathrm{h}$ and $1.76 \mathrm{ng} / \mathrm{mL} \times \mathrm{h}$ for $\mathrm{CBD}$. The metabolites produced a higher $\mathrm{AUC}_{0-8}$ of 

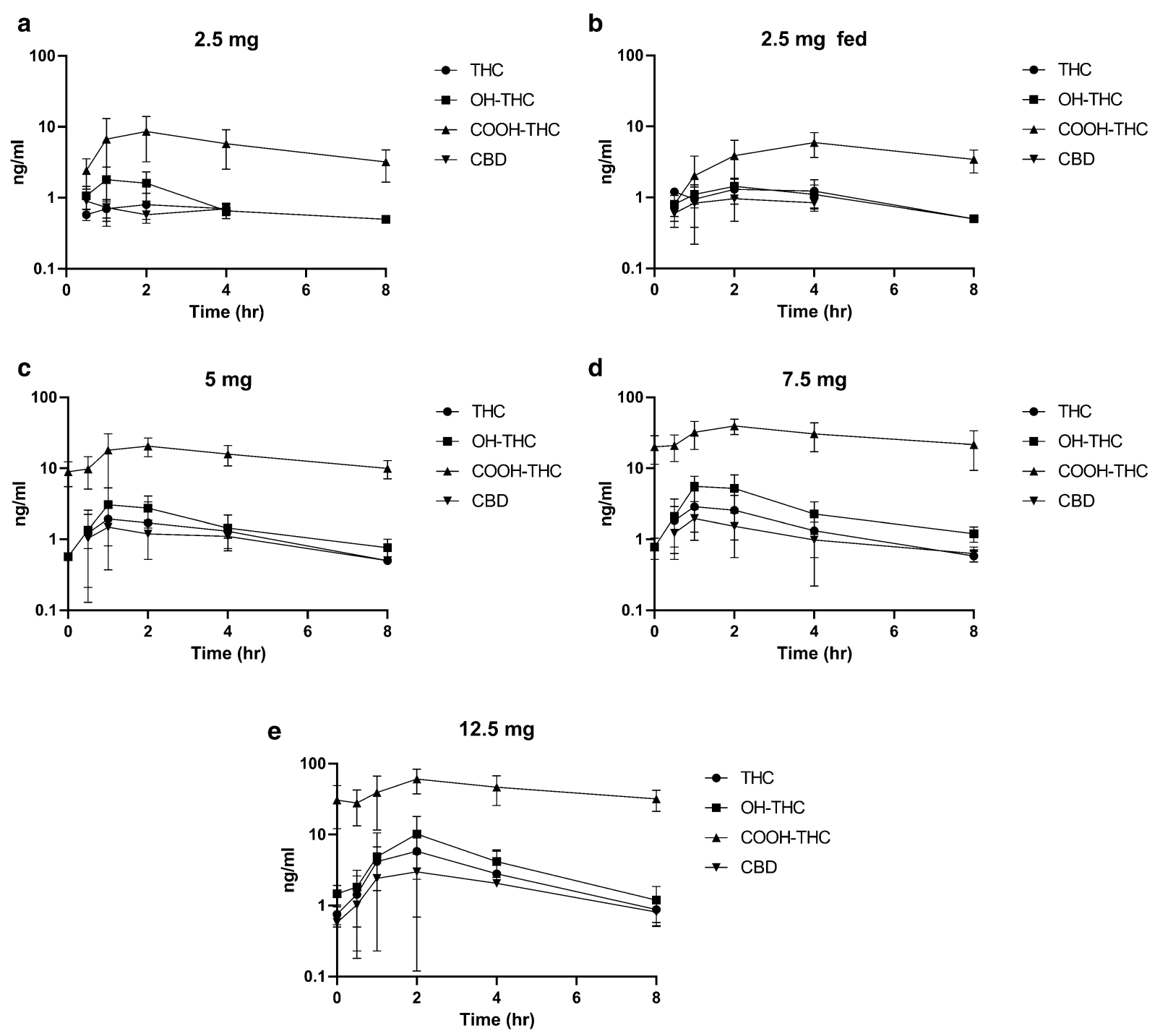

Fig. 1 Mean concentration time profile for all subjects by dose of ZTL-103 and analytes. Error bars are standard deviation

$1.89 \mathrm{ng} / \mathrm{mL} \times \mathrm{h}$ for $\mathrm{OH}-\mathrm{THC}$ and $40.7 \mathrm{ng} / \mathrm{mL} \times$ $\mathrm{h}$ for $\mathrm{COOH}-\mathrm{THC}$.

All analytes had a linear increase in both $C_{\max }$ and $\mathrm{AUC}_{0-8}$ (Table 2, Fig. 2) with no evidence of dose saturation.

Fed vs. fasted: On day 1 the subjects received $2.5 \mathrm{mg}$ of ZTL-103 after a 12-h fast, while on day 8 the subjects received a high fat (approximately $60 \mathrm{~g}$ ) meal $30 \mathrm{~min}$ before the $2.5 \mathrm{mg}$ of ZTL-103. The presence of the high fat meal (Table 2) significantly increased $C_{\max }$ and $\mathrm{AUC}_{0-8}$ (Fig. 3) for THC and CBD, with $t_{1 / 2}$ being unchanged. For THC, $C_{\max }$ increased from $0.83 \mathrm{ng} / \mathrm{mL}$ to $1.52 \mathrm{ng} / \mathrm{mL}(p<0.01)$ and
$\mathrm{AUC}_{0-8}$ from 2.00 to $5.86 \mathrm{ng} / \mathrm{mL} \times \mathrm{h}(p<0.01)$. For $\mathrm{CBD} ;, C_{\max }$ increased from 0.62 to $0.99 \mathrm{ng} /$ $\mathrm{mL}(p<0.01)$ and $\mathrm{AUC}_{0-8}$ from 1.76 to $3.67 \mathrm{ng} /$ $\mathrm{mL} \times \mathrm{h}(p<0.05)$. Although there was no statistical change in $T_{\max }$ there was a tendency for the fed $2.5 \mathrm{mg}$ dose to have a longer time to $C_{\text {max }}$. Although the parent compound THC had an increase in both $C_{\max }$ and $\mathrm{AUC}_{0-8}$, the metabolites both had significant decreases in $C_{\max }$ and no change in $\mathrm{AUC}_{0-8}$. For OH-THC, $C_{\max }$ went from 1.80 to $1.28 \mathrm{ng} / \mathrm{mL}(p<0.05)$ and $\mathrm{AUC}_{0-8}$ from 4.89 to $4.92 \mathrm{ng} / \mathrm{mL} \times \mathrm{h}$; for COOH-THC, $C_{\max }$ went from $9.49 \mathrm{ng} / \mathrm{mL}$ to $6.29 \mathrm{ng} / \mathrm{mL}(p<0.05)$ and $\mathrm{AUC}_{0-8}$ from 40.7 to 
Table 2 Summary of pharmacokinetic parameters for ZTL-103

\begin{tabular}{|c|c|c|c|c|c|c|}
\hline \multirow[t]{2}{*}{ Analyte } & \multicolumn{6}{|c|}{ ZTL-103 average \pm SD $(N)$} \\
\hline & $2.5 \mathrm{mg}$ & $2.5 \mathrm{mg}$ fed & $\begin{array}{l}\text { GMR }^{a}(95 \% \\
\text { CI })\end{array}$ & $5 \mathrm{mg}$ & $7.5 \mathrm{mg}$ & $12.5 \mathrm{mg}$ \\
\hline \multicolumn{7}{|l|}{ THC } \\
\hline$C_{\max }(\mathrm{ng} / \mathrm{mL})$ & $\begin{array}{l}0.83 \pm 0.29 \\
\quad(9)\end{array}$ & $\begin{array}{l}1.52 \pm 0.55 \\
(9)\end{array}$ & $1.8(1.1-2.8)$ & $\begin{array}{l}2.56 \pm 1.70 \\
(8)\end{array}$ & $\begin{array}{l}3.84 \pm 1.62 \\
\quad(7)\end{array}$ & $\begin{array}{l}7.74 \pm 5.14 \\
(7)\end{array}$ \\
\hline$T_{\max }(\mathrm{h})$ & $\begin{array}{l}1.67 \pm 1.09 \\
(9)\end{array}$ & $\begin{array}{l}2.78 \pm 1.20 \\
\quad(9)\end{array}$ & & $\begin{array}{l}2.06 \pm 1.32 \\
\quad(8)\end{array}$ & $\begin{array}{l}1.36 \pm 0.63 \\
\quad(7)\end{array}$ & $\begin{array}{l}2.14 \pm 0.90 \\
\quad(7)\end{array}$ \\
\hline $\begin{array}{l}\mathrm{AUC}_{0-8}(\mathrm{ng} / \mathrm{mL} \times \\
\text { h) }\end{array}$ & $\begin{array}{l}2.00 \pm 1.38 \\
(9)\end{array}$ & $\begin{array}{l}5.86 \pm 2.07 \\
(9)\end{array}$ & $3.4(1.9-5.9)$ & $\begin{array}{l}6.04 \pm 2.07 \\
(8)\end{array}$ & $\begin{array}{l}10.6 \pm 3.84 \\
(7)\end{array}$ & $\begin{array}{l}19.4 \pm 9.62 \\
(7)\end{array}$ \\
\hline$t_{1 / 2}(\mathrm{~h})$ & $\begin{array}{l}2.60 \pm 0.53 \\
(4)\end{array}$ & $\begin{array}{l}2.63 \pm 0.43 \\
(4)\end{array}$ & & $\begin{array}{l}2.47 \pm 0.88 \\
(6)\end{array}$ & $\begin{array}{l}2.41 \pm 0.62 \\
\quad(7)\end{array}$ & $\begin{array}{l}3.40 \pm 2.70 \\
(6)\end{array}$ \\
\hline \multicolumn{7}{|l|}{ OH-THC } \\
\hline$C_{\max }(\mathrm{ng} / \mathrm{mL})$ & $\begin{array}{l}1.80 \pm 0.83 \\
(9)\end{array}$ & $\begin{array}{l}1.28 \pm 0.51 \\
(9)\end{array}$ & $0.7(0.6-0.9)$ & $\begin{array}{l}3.79 \pm 1.79 \\
(8)\end{array}$ & $\begin{array}{l}6.37 \pm 2.67 \\
(7)\end{array}$ & $\begin{array}{l}11.7 \pm 7.97 \\
(7)\end{array}$ \\
\hline$T_{\max }(\mathrm{h})$ & $\begin{array}{l}1.89 \pm 0.93 \\
(9)\end{array}$ & $\begin{array}{l}2.78 \pm 1.20 \\
(9)\end{array}$ & & $\begin{array}{l}2.13 \pm 1.25 \\
\quad(8)\end{array}$ & $\begin{array}{l}1.57 \pm 0.53 \\
(7)\end{array}$ & $\begin{array}{l}2.14 \pm 0.90 \\
\quad(7)\end{array}$ \\
\hline $\begin{array}{l}\mathrm{AUC}_{0-8}(\mathrm{ng} / \mathrm{mL} \times \\
\text { h) }\end{array}$ & $\begin{array}{l}4.89 \pm 2.40 \\
(9)\end{array}$ & $\begin{array}{l}4.92 \pm 2.05 \\
(9)\end{array}$ & $1.1(0.8-1.3)$ & $\begin{array}{l}10.9 \pm 3.54 \\
(8)\end{array}$ & $\begin{array}{l}20.6 \pm 8.61 \\
(7)\end{array}$ & $\begin{array}{l}35.0 \pm 16.2 \\
\quad(7)\end{array}$ \\
\hline$t_{1 / 2}(\mathrm{~h})$ & $\begin{array}{l}2.57 \pm 0.90 \\
\quad(6)\end{array}$ & $\begin{array}{l}6.20 \pm 5.55 \\
\quad(4)\end{array}$ & & $\begin{array}{l}2.80 \pm 0.56 \\
\quad(5)\end{array}$ & $\begin{array}{l}2.70 \pm 0.49 \\
\quad(7)\end{array}$ & $\begin{array}{l}3.40 \pm 1.74 \\
\quad(6)\end{array}$ \\
\hline \multicolumn{7}{|l|}{$\mathrm{COOH}-\mathrm{THC}$} \\
\hline$C_{\max }(\mathrm{ng} / \mathrm{mL})$ & $\begin{array}{l}9.49 \pm 4.55 \\
\quad(9)\end{array}$ & $\begin{array}{l}6.29 \pm 1.91 \\
\quad(9)\end{array}$ & $0.7(0.5-0.9)$ & $\begin{array}{l}24.3 \pm 9.45 \\
\quad(8)\end{array}$ & $\begin{array}{l}42.8 \pm 13.3 \\
\quad(7)\end{array}$ & $\begin{array}{l}66.4 \pm 26.2 \\
\quad(7)\end{array}$ \\
\hline$T_{\max }(\mathrm{h})$ & $\begin{array}{l}2.00 \pm 0.87 \\
\quad(9)\end{array}$ & $\begin{array}{l}4.00 \pm 1.73 \\
\quad(9)\end{array}$ & & $\begin{array}{l}2.25 \pm 1.16 \\
\quad(8)\end{array}$ & $\begin{array}{l}2.14 \pm 0.90 \\
\quad(7)\end{array}$ & $\begin{array}{l}3.00 \pm 2.38 \\
\quad(7)\end{array}$ \\
\hline $\begin{array}{l}\mathrm{AUC}_{0-8}(\mathrm{ng} / \mathrm{mL} \times \\
\mathrm{h})\end{array}$ & $\begin{array}{l}40.7 \pm 22.8 \\
\quad(9)\end{array}$ & $\begin{array}{l}31.4 \pm 11.2 \\
\quad(9)\end{array}$ & $0.8(0.6-1.0)$ & $\begin{array}{l}118 \pm 32.8 \\
\quad(8)\end{array}$ & $\begin{array}{l}231 \pm 83.3 \\
\quad(7)\end{array}$ & $\begin{array}{l}343 \pm 126 \\
\quad(7)\end{array}$ \\
\hline$t_{1 / 2}(\mathrm{~h})$ & $\begin{array}{l}4.00 \pm 1.24 \\
\quad(8)\end{array}$ & $\begin{array}{l}4.02 \pm 0.07 \\
\quad(2)\end{array}$ & & $\begin{array}{l}2.47 \pm 0.88 \\
\quad(6)\end{array}$ & $\begin{array}{l}5.85 \pm 1.71 \\
(6)\end{array}$ & $\begin{array}{l}5.46 \pm 1.44 \\
\quad(5)\end{array}$ \\
\hline \multicolumn{7}{|l|}{$\mathrm{CBD}$} \\
\hline$C_{\max }(\mathrm{ng} / \mathrm{mL})$ & $\begin{array}{l}0.62 \pm 0.19 \\
\quad(9)\end{array}$ & $\begin{array}{l}0.99 \pm 0.45 \\
\quad(9)\end{array}$ & $1.5(1.0-2.3)$ & $\begin{array}{l}1.51 \pm 0.55 \\
\quad(8)\end{array}$ & $\begin{array}{l}2.26 \pm 0.95 \\
\quad(7)\end{array}$ & $\begin{array}{l}4.53 \pm 2.82 \\
\quad(7)\end{array}$ \\
\hline$T_{\max }(\mathrm{h})$ & $\begin{array}{l}1.83 \pm 1.00 \\
\quad(9)\end{array}$ & $\begin{array}{l}2.78 \pm 1.20 \\
\quad(9)\end{array}$ & & $\begin{array}{l}1.75 \pm 1.04 \\
\quad(8)\end{array}$ & $\begin{array}{l}1.64 \pm 1.18 \\
\quad(7)\end{array}$ & $\begin{array}{l}2.29 \pm 1.25 \\
\quad(7)\end{array}$ \\
\hline $\begin{array}{l}\mathrm{AUC}_{0-8}(\mathrm{ng} / \mathrm{mL} \times \\
\mathrm{h})\end{array}$ & $\begin{array}{l}1.76 \pm 0.84 \\
(9)\end{array}$ & $\begin{array}{l}3.67 \pm 1.57 \\
(9)\end{array}$ & $2.1(1.4-3.4)$ & $\begin{array}{l}5.09 \pm 1.80 \\
(8)\end{array}$ & $\begin{array}{l}7.47 \pm 2.95 \\
(7)\end{array}$ & $\begin{array}{l}13.3 \pm 6.67 \\
(7)\end{array}$ \\
\hline
\end{tabular}


Table 2 continued

\begin{tabular}{|c|c|c|c|c|c|c|}
\hline \multirow[t]{2}{*}{ Analyte } & \multicolumn{6}{|c|}{ ZTL-103 average \pm SD $(N)$} \\
\hline & $2.5 \mathrm{mg}$ & $2.5 \mathrm{mg}$ fed & $\begin{array}{l}\text { GMR }^{a}(95 \% \\
\text { CI })\end{array}$ & $5 \mathrm{mg}$ & $7.5 \mathrm{mg}$ & $12.5 \mathrm{mg}$ \\
\hline$t_{1 / 2}(\mathrm{~h})$ & $\begin{array}{l}4.25 \pm 0.54 \\
(4)\end{array}$ & $\begin{array}{l}2.95 \pm 0.66 \\
(4)\end{array}$ & & $\begin{array}{l}4.54 \pm 2.41 \\
\quad(7)\end{array}$ & $\begin{array}{l}3.47 \pm 0.86 \\
\quad(6)\end{array}$ & $\begin{array}{c}3.56 \pm 2.37 \\
(6)\end{array}$ \\
\hline
\end{tabular}

${ }^{\mathrm{a}}$ Geometric mean ratio of fed $\mathrm{v}$ fasted
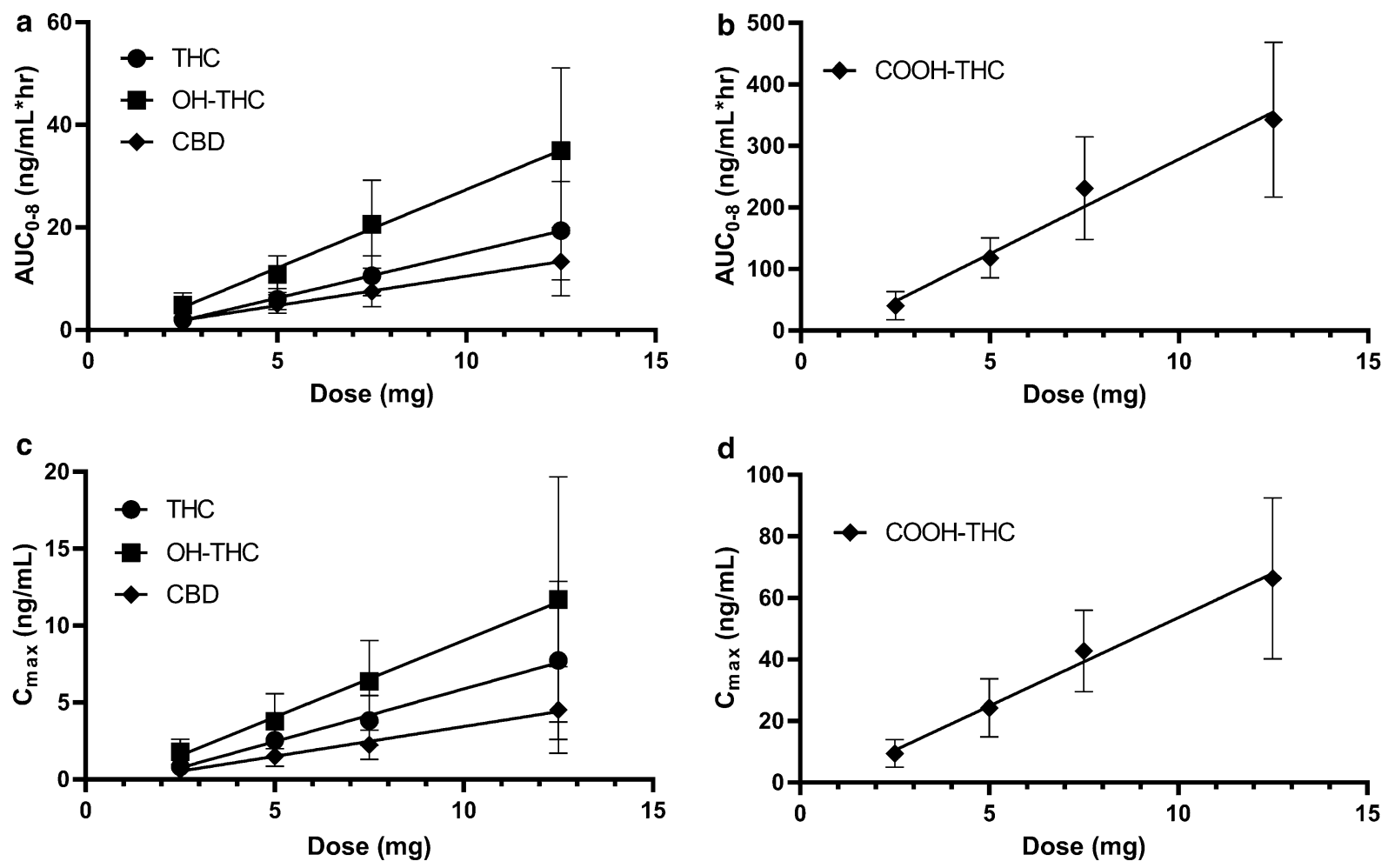

Fig. 2 Dose response for AUC of ZTL-103 (top row) and $C_{\max }$ (bottom row); the graphs on the left have THC, OHTHC, and CBD, and the graph on the right shows COOH-THC. Error bars are standard deviation

$34.1 \mathrm{ng} / \mathrm{mL} \times \mathrm{h}$. There was a significant delay in the $T_{\max }$ for both OH-THC $(p<0.05)$ and COOH-THC $(p<0.01)$, and this delay in $T_{\max }$ meant that it was not possible to determine $t_{1 / 2}$ for many of the subjects.

\section{Safety Parameters}

Adverse events (AE): Eight participants (88.9\%) reported at least one AE. A total of 62 AEs occurred in these eight participants throughout the study. None of these events were classified as severe. Four events were classified as moderate severity (back pain, confusional state, pain in extremity [left arm], and neck pain). The remaining 58 AEs were classified as mild severity.

No SAEs were reported. Seven of the eight participants $(87.5 \%)$ reported at least one $\mathrm{AE}$ that was considered by the site investigator to be related to the study medication, including 


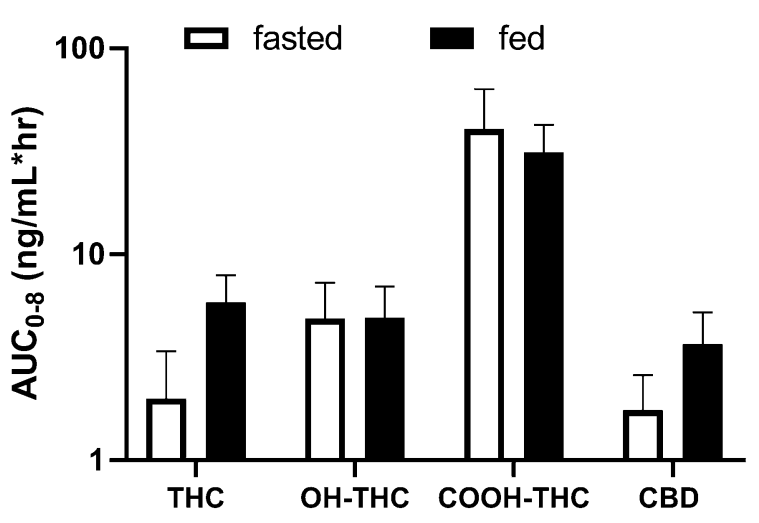

Fig. 3 AUC for all analytes, comparing a $2.5 \mathrm{mg}$ dose of ZTL-103 with and without food. Error bars are standard deviation

ratings of definitely related, probably related, or possibly related (Table 3). Of all AEs, 30 in total were considered to be study medication-related (48.4\%, 30 of 62$)$. The most frequently occurring study medication-related $\mathrm{AE}$ was "feeling high" (20.0\%, 6 of 30), which occurred during the stages of higher dosing (especially a total daily dose of $15 \mathrm{mg}$ THC/15 mg CBD); followed by headache $(16.7 \%, 5$ of 30$)$, occurring at most stages throughout the study.

Of the 30 AEs considered to be study medication-related, nine (30\%) were unresolved. They included dizziness, nausea, headache, insomnia, increased appetite, dry mouth, agitation, and lethargy. Of the 21 AEs that had a stop date during the trial, 17 stopped the same day the event started.

Oral dosing of the study medication was well tolerated. Two participants experienced 'dry mouth' events during the study at the higher dosing stages (stage 3 and 4). These were recorded in the adverse event log, classified as mild severity.

\section{Physical Examination and Vital Signs}

Most participants recorded no changes in general appearance and physical condition across the duration of the study.

No significant changes were observed in mean temperature, pulse, and respiratory rate across the duration of the study. From day 1 of the study, participants showed significant reductions in mean blood pressure observations compared to baseline continuing to decline up to day 29. Mean baseline systolic blood pressure was $147.0 \mathrm{mmHg}(\mathrm{SD}=24.1)$ and mean diastolic blood pressure was $90.7 \mathrm{mmHg}$ ( $\mathrm{SD}=$ 12.7). Mean day 29 pre-dose blood pressure was systolic $127.0 \mathrm{mmHg} \quad(\mathrm{SD}=13.5, t(6)=3.38$, $p=0.015)$ and diastolic $77.3 \mathrm{mmHg}(\mathrm{SD}=6.7$, $t(6)=4.56, p=0.004$ ). On day 36 (after 7 days without study medication) mean participant blood pressure had risen to baseline levels for both systolic $(M=141.7 \mathrm{mmHg}, \quad \mathrm{SD}=26.2$, $t(2)=0.69, \quad p=0.560) \quad$ and diastolic $(M=90.3 \mathrm{mmHg}, \quad \mathrm{SD}=7.2, \quad t(2)=0.79$, $p=0.510)$.

\section{Secondary Outcomes}

Pain: Table 4 shows individual pain scores based on the BPI over the duration of the study. The data shows considerable inter-individual variability. There was no significant change in mean pain severity throughout the duration of the trial, according to the BPI. However, from approximately day 17 there was a consistent reduction in mean pain interference scores through to day 30. An increase in mean pain interference scores was observed from day 31 (after cessation of medication). Aggregated pain scores are available in Supplementary Material Fig. 1.

There was no self-reported change, either increase or decrease, in pain medications for any participant during the trial.

Mood: Compared to baseline $(M=10.22$, $\mathrm{SD}=6.69)$, mean depression score on the DASS had dropped significantly at day $8(M=7.56$, $\mathrm{SD}=6.44, t(8)=3.88, p=0.005)$ and continued to fall through to day $36(M=4.29, \mathrm{SD}=4.11$, $t(6)=4.24, p=0.005)$. Mean anxiety scores also fell significantly by day $15(M=5.38, \mathrm{SD}=5.45$, $t(7)=2.95, p=0.022)$, as did stress scores by day $22 \quad(M=5.75, \quad \mathrm{SD}=4.33, \quad t(7)=4.33$, $p=0.003)$ through to day $36(M=6.86, \mathrm{SD}=$ 5.73, $t(6)=5.28, p=0.002$ ) (see Table 5 and Supplementary Material Fig. 2).

Sleep: Mean scores for clinical insomnia on the ISI were of moderate severity at baseline 
Table 3 Number of study medication-related adverse events $(n=30)$ grouped by System Organ Class (SOC) and preferred term, then split by dose regime

\begin{tabular}{lllllll}
\hline $\begin{array}{l}\text { Event (System Organ Class/ } \\
\text { preferred term) }\end{array}$ & \multirow{2}{*}{ Number } & \multicolumn{2}{l}{ Dose regime } \\
\cline { 3 - 7 } & & Stage 1 & Stage 2 & Stage 3 & Stage 4 & Stage 5 \\
\hline Number of participants with $\geq 1$ & 7 of 9 & 2 of 9 & 2 of 9 & 5 of 8 & 5 of 8 & 2 of 7 \\
event & $(77.8 \%)$ & $(22.2 \%)$ & $(22.2 \%)$ & $(62.5 \%)$ & $(62.5 \%)$ & $(28.6 \%)$
\end{tabular}

Gastrointestinal disorders

Dry mouth

Nausea

$\begin{array}{ll}2 & 0 \\ 1 & 0\end{array}$

$\begin{array}{ll}0 & 1 \\ 1 & 0\end{array}$

$\begin{array}{ll}1 & 0 \\ 0 & 0\end{array}$

General disorders and administration site conditions

$$
\text { Lethargy }
$$

$$
1
$$

0

$$
0
$$

1

0

0

Metabolism and nutrition disorders

Increased appetite

$1 \quad 0$

0

0

1

0

0

Musculoskeletal and connective tissue disorders

Pain in extremity

1

1

0

0

0

0

Nervous system disorders

Dizziness

Gait disturbance

Headache

Migraine

Sedation

Psychiatric disorders

Abnormal dreams

Agitation

Confusional state

Euphoric Mood

Insomnia

Total

2
1
5
2
1
1
3
1
6
2
30

$\begin{array}{llll}1 & 1 & 0 & 0 \\ 0 & 1 & 0 & 0 \\ 0 & 1 & 2 & 1 \\ 0 & 2 & 0 & 0 \\ 0 & 0 & 0 & 0\end{array}$

Study medication related $=$ combined categories of definitely related, probably related, and possibly related

Stage $1=$ single dose of $2.5 \mathrm{mg} \mathrm{THC} / 2.5 \mathrm{mg} \mathrm{CBD}$ followed by a 7 -day washout period

Stage 2 = single dose of $2.5 \mathrm{mg}$ THC/2.5 mg CBD followed by high fat meal, then receive a total daily dose of $5 \mathrm{mg}$ THC/ $5 \mathrm{mg}$ CBD for 1 week

Stage 3 = single dose of $5 \mathrm{mg}$ THC/5 $\mathrm{mg} \mathrm{CBD}$ and then receive a total daily dose of $10 \mathrm{mg}$ THC/10 $\mathrm{mg}$ CBD for 1 week Stage $4=$ single dose of $7.5 \mathrm{mg}$ THC/7.5 $\mathrm{mg} \mathrm{CBD}$ and then receive a total daily dose of $15 \mathrm{mg}$ THC/15 $\mathrm{mg}$ CBD for 1 week

Stage $5=$ single dose of $12.5 \mathrm{mg}$ THC/12.5 mg CBD on 1 day followed by a 7 -day washout 
Table 4 Individual Brief Pain Inventory (BPI) scores over time

\begin{tabular}{|c|c|c|c|c|c|c|c|}
\hline Participant & $\begin{array}{l}\text { Baseline } \\
\text { (day 0) }\end{array}$ & $\begin{array}{l}\text { Day 1-7 } \\
\text { average }^{a}\end{array}$ & $\begin{array}{l}\text { Day 8-14 } \\
\text { average }^{\mathrm{a}}\end{array}$ & $\begin{array}{l}\text { Day } 15-21 \\
\text { average }^{a}\end{array}$ & $\begin{array}{l}\text { Day 22-28 } \\
\text { average }^{\text {a }}\end{array}$ & $\begin{array}{l}\text { Day 29-35 } \\
\text { average }^{a}\end{array}$ & Day 36 \\
\hline \multicolumn{8}{|c|}{ BPI severity scores } \\
\hline 1 & 5.00 & 6.93 & 5.79 & 4.79 & 4.57 & 4.36 & 6.25 \\
\hline 2 & 4.75 & 5.07 & 4.75 & 3.64 & 1.71 & 3.21 & 5.75 \\
\hline 3 & 7.50 & 7.46 & 6.82 & 6.25 & 5.86 & 7.14 & 7.00 \\
\hline 4 & 5.25 & 6.00 & 6.42 & 5.18 & 5.32 & 7.89 & 8.00 \\
\hline 5 & 8.00 & 6.36 & 7.32 & 4.64 & 5.38 & NR & NR \\
\hline 6 & 4.75 & 4.75 & 4.11 & 4.20 & 4.50 & 4.11 & 4.00 \\
\hline 7 & 6.00 & 6.29 & 4.77 & NR & NR & NR & NR \\
\hline 8 & 5.00 & 3.86 & 3.61 & 3.36 & 3.93 & 3.89 & 2.50 \\
\hline 9 & 3.50 & 4.32 & 4.43 & 4.46 & 4.46 & 4.80 & 4.63 \\
\hline $\begin{array}{r}\text { Mean } \\
(\mathrm{SD})\end{array}$ & $5.53(1.42)$ & $5.67(1.23)$ & $5.33(1.30)$ & $4.56(0.90)$ & $4.47(1.27)$ & $5.06(1.76)$ & $\begin{array}{l}5.45 \\
\quad(1.88)\end{array}$ \\
\hline \multicolumn{8}{|c|}{ BPI interference scores } \\
\hline 1 & 4.67 & 5.02 & 2.93 & 2.62 & 2.88 & 4.00 & 5.33 \\
\hline 2 & 4.71 & 4.69 & 5.47 & 4.86 & 1.80 & 3.14 & 4.29 \\
\hline 3 & 9.14 & 8.67 & 7.78 & 7.12 & 6.45 & 7.02 & 8.00 \\
\hline 4 & 6.29 & 4.61 & 5.71 & 5.04 & 4.06 & 4.35 & 4.71 \\
\hline 5 & 4.29 & 2.67 & 2.78 & 1.20 & 1.14 & NR & NR \\
\hline 6 & 3.57 & 3.71 & 2.92 & 3.12 & 3.41 & 2.67 & 2.43 \\
\hline 7 & 8.43 & 6.04 & 4.18 & NR & NR & NR & NR \\
\hline 8 & 7.86 & 6.67 & 5.45 & 4.47 & 5.06 & 5.43 & 4.00 \\
\hline 9 & 6.71 & 7.08 & 7.33 & 7.30 & 7.58 & 7.62 & 7.43 \\
\hline $\begin{array}{r}\text { Mean } \\
(\mathrm{SD})\end{array}$ & $6.19(1.99)$ & $5.47(1.84)$ & $4.95(1.88)$ & $4.47(2.12)$ & $4.05(2.22)$ & $4.89(1.89)$ & $\begin{array}{l}5.17 \\
\quad(1.96)\end{array}$ \\
\hline
\end{tabular}

$N R$ not recorded, SD standard deviation

${ }^{a}$ Average of the daily BPI scores across each week

$(M=17.44, \mathrm{SD}=5.75)$ dropping significantly to sub-threshold by day $22(M=8.93, \mathrm{SD}=4.05$, $t(6)=5.41, p=0.002)$, whilst sleep quality improved significantly from not really satisfactory $(M=3.22, \mathrm{SD}=0.83)$ to somewhat satisfactory by day $22 \quad(M=2.00, \quad \mathrm{SD}=1.07$, $t(7)=3.21, \quad p=0.015) \quad$ (see Supplementary Material Fig. 3).
Self-reported total hours of sleep in the previous week was $39.11(\mathrm{SD}=9.28)$ at baseline, rising to $52.78(\mathrm{SD}=13.65)$ at day 29 , then dropping slightly at day $36(M=46.75, S D=$ 9.91). This increase was not significant (day 29: $t(5)=-1.73, \quad p=0.143 ; \quad$ day $36: t(3)=-1.38$, $p=0.260)$. 


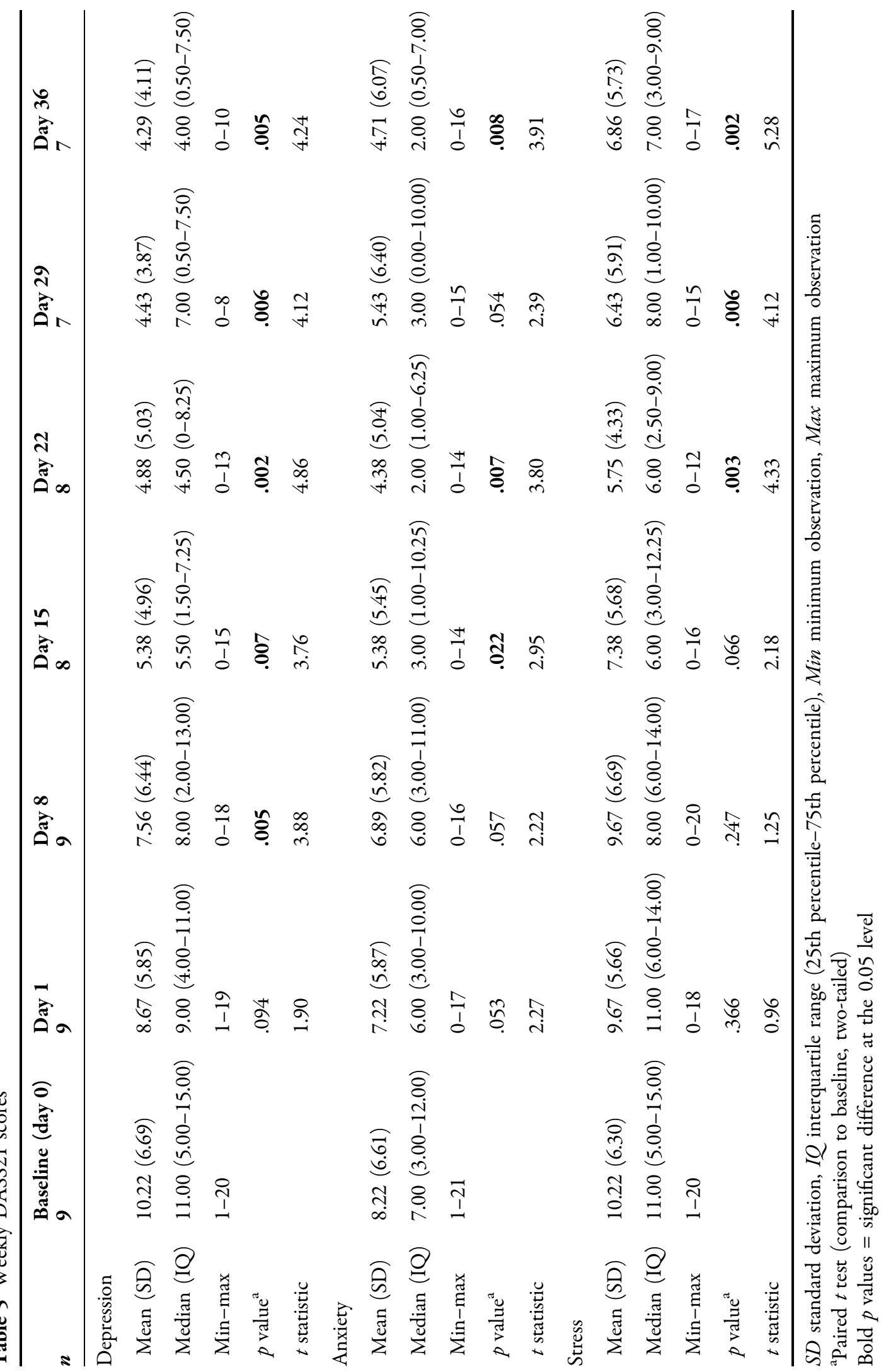


Sleep diary: Compared to week $1(M=2.41$, $\mathrm{SD}=0.59)$, perceived sleep onset latency significantly improved from week $2(M=1.87$, $\mathrm{SD}=0.52, t(7)=2.96, p=0.021)$. No significant change in total sleep time was reported. Sleep quality ratings were generally unchanged.

\section{DISCUSSION}

In this study, THC, OH-THC, COOH-THC, and CBD were detected in most sampled time points. The concentrations of THC were generally higher than the concentrations of CBD. Both of the metabolites OH-THC (1.1-2.6 times) and COOH-THC (2.1-37 times) had higher concentrations than the parent THC at the equivalent dose and time. There was a linear dose-response relationship for both $C_{\max }$ and $\mathrm{AUC}_{0-8}$, with increasing doses of ZTL-103 for THC, OH-THC, COOH-THC, and CBD. A high fat meal $30 \mathrm{~min}$ before a dose of ZTL-103 significantly increased both $C_{\max }$ and $\mathrm{AUC}_{0-8}$, for THC and CBD, but did not increase OH-THC or COOH-THC. The high fat meal also generally delayed the $T_{\max }$ by at least $1 \mathrm{~h}$. The $t_{1 / 2}$ did not change with increasing dose which was $2.5 \mathrm{~h}$ for THC, $2.7 \mathrm{~h}$ for OH-THC, $5.0 \mathrm{~h}$ for COOH-THC, and $3.6 \mathrm{~h}$ for CBD.

There is limited pharmacokinetic data on medicinal cannabis formulations. This is even more relevant to oral formulations of THC/CBD combinations. Guy and Robson [30] demonstrated the pharmacokinetics for the sublingual Sativex ${ }^{\circledR}$, a 1:1 THC/CBD formulation, as well as buccal and oral administration at a dose of $10 \mathrm{mg}$ THC/10 mg CBD. They observed a mean $T_{\text {max }}$ of around $98 \mathrm{~min}$ for CBD, THC, and $\mathrm{OH}-$ THC, and average $C_{\max }$ of $2.5 \mathrm{ng} / \mathrm{mL}, 5.5 \mathrm{ng} /$ $\mathrm{mL}$, and $6.2 \mathrm{ng} / \mathrm{mL}$ for $\mathrm{CBD}$, THC, and $\mathrm{OH}-$ THC, respectively. They also showed an average $\mathrm{AUC}_{0-\mathrm{t}}$ of $6.8,13.4$, and $25.3 \mathrm{ng} / \mathrm{mL} \times \mathrm{h}$ for CBD, THC, and OH-THC, respectively. Our results are consistent with Guy and Robson [29], demonstrating a similar pharmacokinetic profile, similar variation and their data would fit between our $7.5 \mathrm{mg}$ THC/7.5 $\mathrm{mg}$ CBD and $12.5 \mathrm{mg}$ THC/12.5 mg CBD as would be expected from the linear relationship that we have observed. Guy and Robson [30] showed a slightly lower $t_{1 / 2}$ of $1.4,1.8$, and $2.1 \mathrm{~h}$ for CBD, THC, and OH-THC compared to ours of around $3 \mathrm{~h}$; this may be due to the increased number of data points (20 to our 6 ) used to fit their pharmacokinetic profile.

In general, the concentration of all analytes increased until $2 \mathrm{~h}$ after administration, then decreased to approximately pre-dose levels by $8 \mathrm{~h}$. This would support twice daily dosing regimen used in this study. The safety profile of ZTL-103 is also consistent with that of Sativex ${ }^{\circledR}$ [30], although the incidence of both euphoria and headache were higher than has been observed in other studies. For example, Robson [31] reported a $2 \%$ incidence of euphoria. The results indicate that this cannabinoid formulation (ZTL-103) is safe and well tolerated at all dosage levels tested. Significant improvements in mean participants' blood pressure was an unexpected finding which warrants further investigation. However, there is no evidence that medicinal cannabis has a positive effect on cardiovascular health [32]. High between-participant variability on pharmacokinetic and effect parameters supports personalized dosing and "start low-go slow titration", as recommended by others $[33,34]$. In this small sample size there did not appear to be a relationship between BMI and AUC for either THC or CBD. Therefore it is unlikely that BMI is influencing the inter-individual variability.

This study has a number of limitations. The study was primarily a pharmacokinetic study designed to inform dosing in a subsequent RCT. The design, with a small sample size and lack of control condition, whilst appropriate for a pharmacokinetic study, does not provide reliable data to address the gaps in our understanding of the analgesic or opioid-sparing effects of cannabinoids. Future trials should monitor liver enzyme functions as elevated levels have been observed by others, although at dosages significantly greater than our study [35]. Observed improvements in pain interference scores, mood, and sleep parameters may well be attributable to placebo effect. The opioid-sparing effects of ZTL-103 in CNCP should be investigated as part of a larger randomized placebo-controlled clinical trial. 


\section{CONCLUSIONS}

The evidence base for cannabinoid formulations to treat CNCP is limited by the fact that medicinal cannabis products have historically not undergone the same rigorous regulatory process and developmental safeguards as other therapeutic goods. This process underpins the development of guidelines for indications, dosage, and potential adverse events. Pharmacokinetic data are generally obtained from healthy volunteers but cannot necessarily be extrapolated to clinical populations with physical and psychological comorbidities, polypharmacy, and other vulnerabilities. This study represents the necessary first step in this process so that practitioners can prescribe cannabinoid formulations in patients on high dose opioids with confidence underpinned by robust safety and efficacy data.

\section{ACKNOWLEDGEMENTS}

The authors acknowledge the contribution of Professor Alistair Vickery and Ms Tracie Ermenwein of Emerald Clinics for recruitment of trial participants and data collection; Dr Michelle Williams, Medicinal Cannabinoid Method Development, University of Newcastle-Faculty of Health and Medicine-School of Medicine and Public Health for assistance with pharmacokinetic analysis and interpretation; and Dr Jennifer Walsh from the Centre for Sleep Science, University of Western Australia for assistance with analysis of sleep data. We thank the participants for their participation in the study.

Funding. This study was funded by Zelira Therapeutics Limited (ZTL). The funding organization contributed to the design of the study but was not involved in data analysis, interpretation or manuscript preparation. Funds from Zelira Therapeutics Limited were used to pay for the journal's Rapid Service Fee.

Authorship. All named authors meet the International Committee of Medical Journal
Editors (ICMJE) criteria for authorship of this article, take responsibility for the integrity of the work as a whole, and have given their approval for this version to be published.

Authors' Contributions. Yvonne Bonomoconcept and design, drafting the manuscript; Amanda Norman-concept and design, drafting the manuscript; Lisa Collins-statistical analysis, drafting the manuscript; Helen O'Neill-recruitment, data collection, review of manuscript; Peter Galettis-pharmacokinetic analysis, drafting the manuscript; Jane Trincaconcept and design, review of manuscript; Nigel Strauss-concept and design, review of manuscript; Jennifer Martin-pharmacokinetic analysis, review of manuscript; David Castleconcept and design; drafting of manuscript.

Disclosures. Authors Yvonne Bonomo and Jennifer Martin are Chief Investigators at the Australian Centre for Cannabinoid Clinical and Research Excellence (ACRE), a National Health and Medical Research Council funded Centre of Research Excellence. David Castle is currently Director, Centre for Addictions and Mental Health, Toronto, Canada. Authors Amanda Norman, Lisa Collins, Helen O'Neill, Peter Galettis, Nigel Strauss, and Jane Trinca have nothing to disclose.

Compliance with Ethics Guidelines. The study protocol, Patient Information and Consent Form (PICF), and Investigator Brochure were approved by the St Vincent's Hospital Melbourne (SVHM) Human Research Ethics Committee (HREC 064/19) for both study sites. The study was conducted in accordance with the Helsinki Declaration of 1994 and subsequent amendments. Participation was voluntary under conditions of informed consent. The trial was prospectively registered with the Australian New Zealand Clinical Trials Register (CT2019-CTN-01224-1).

Data Availability. The data that support the findings of this study are available from the corresponding author upon reasonable request. 
Open Access. This article is licensed under a Creative Commons Attribution-NonCommercial 4.0 International License, which permits any non-commercial use, sharing, adaptation, distribution and reproduction in any medium or format, as long as you give appropriate credit to the original author(s) and the source, provide a link to the Creative Commons licence, and indicate if changes were made. The images or other third party material in this article are included in the article's Creative Commons licence, unless indicated otherwise in a credit line to the material. If material is not included in the article's Creative Commons licence and your intended use is not permitted by statutory regulation or exceeds the permitted use, you will need to obtain permission directly from the copyright holder. To view a copy of this licence, visit http://creativecommons.org/licenses/by$\mathrm{nc} / 4.0 /$.

\section{REFERENCES}

1. Pertwee RG. Neuropharmacology and therapeutic potential of cannabinoids. Addict Biol. 2000;5(1): 37-46.

2. Campos AC, Moreira FA, Gomes FV, Del Bel EA, Guimaraes FS. Multiple mechanisms involved in the large-spectrum therapeutic potential of cannabidiol in psychiatric disorders. Philos Trans R Soc Biol Sci. 2012;367(1607):3364-78.

3. Zuardi A, Cosme RA, Graeff FG. Human experimental. Anxiety. 1993;7(1):82-8.

4. Linge R, Jiménez-Sánchez L, Campa L, et al. Cannabidiol induces rapid-acting antidepressantlike effects and enhances cortical 5-HT/glutamate neurotransmission: role of 5-HT1A receptors. Neuropharmacology. 2016;103:16-26. https://doi.org/ 10.1016/j.neuropharm.2015.12.017.

5. Campos AC, Fogaca MV, Sonego AB, Guimarães FS. Cannabidiol, neuroprotection and neuropsychiatric disorders. Pharmacol Res. 2016. https://doi. org/10.1016/j.phrs.2016.01.033.

6. Silveira JW, Issy AC, Castania VA, et al. Protective effects of cannabidiol on lesion-induced intervertebral disc degeneration. PLoS ONE. 2014;9(12): 1-13. https://doi.org/10.1371/journal.pone.0113 161 .
7. Russo EB, Guy GW. A tale of two cannabinoids: the therapeutic rationale for combining tetrahydrocannabinol and cannabidiol. Med Hypotheses. 2006;66:234-46.

8. Corroon JM Jr, Mischley LK, Sexton M. Cannabis as a substitute for prescription drugs-a cross-sectional study. J Pain Res. 2017;10:989.

9. Lynch ME, Clark AJ. Cannabis reduces opioid dose in the treatment of chronic non-cancer pain. J Pain Symptom Manag. 2003;25:496-8.

10. Johnson JR, Burnell-Nugent M, Lossignol D, et al. Multicenter, double-blind, randomized, placebocontrolled, parallel-group study of the efficacy, safety, and tolerability of THC:CBD extract and THC extract in patients with intractable cancer-related pain. J Pain Symptom Manag. 2010;39: 167-79.

11. Fallon MT, Albert Lux E, McQuade R, et al. Sativex oromucosal spray as adjunctive therapy in advanced cancer patients with chronic pain unalleviated by optimized opioid therapy: two doubleblind, randomized, placebo-controlled phase 3 studies. Br J Pain. 2017;11(3):119-33.

12. Lichtman AH, Lux EA, McQuade R, et al. Results of a double-blind, randomized, placebo-controlled study of nabiximols oromucosal spray as an adjunctive therapy in advanced cancer patients with chronic uncontrolled pain. J Pain Symptom Manage. 2018;55(2):179-88.

13. Seeling W, Kneer L, Büchele B, et al. Delta (9)-tetrahydrocannabinol and the opioid receptor agonist piritramide do not act synergistically in postoperative pain. Anaesthesist. 2006;55(4): 391-400.

14. Deshpande A, Mailis-Gagnon A, Zoheiry N, Lakha SF. Efficacy and adverse effects of medical marijuana for chronic noncancer pain: systematic review of randomized controlled trials. Can Fam Physician. 2015;61(8):e372-81.

15. Meng H, Johnston B, Englesakis M, Moulin DE, Bhatia A. Selective cannabinoids for chronic neuropathic pain: a systematic review and meta-analysis. Anesth Analg. 2017;125(5):1638-52.

16. Nielsen S, Sabioni P, Trigo JM, et al. Opioid-sparing effect of cannabinoids: a systematic review and meta-analysis. Neuropsychopharmacology. 2017;42(9):1752-65.

17. Stockings E, Campbell G, Hall WD, et al. Cannabis and cannabinoids for the treatment of people with chronic noncancer pain conditions: a systematic review and meta-analysis of controlled and observational studies. Pain. 2018;159(10):1932-54. 
18. Häuser W, Welsch P, Klose P, Radbruch L, Fitzcharles MA. Efficacy, tolerability and safety of cannabis-based medicines for cancer pain. Der Schmerz. 2019;33(5):424-36.

19. Therapeutic Goods Administration. Guidance for the use of medicinal cannabis and cannabinoids in the treatment of chronic non-cancer pain. Version 1 December 2017. Department of Health, Australia.

20. Krebs MO, Kebir O, Jay TM. Exposure to cannabinoids can lead to persistent cognitive and psychiatric disorders. Eur J Pain. 2019;23(7):1225-33.

21. Gong L, Stamer UM, Tzvetkov MV, Altman RB, Klein TE. PharmGKB summary: tramadol pathway. Pharmacogenet Genomics. 2014;24(7):374-80. https://doi.org/10.1097/FPC.0000000000000057. PMID:24849324;PMCID:PMC4100774.

22. Alsherbiny MA, Guang C. Medicinal cannabispotential drug interactions. Medicines. 2018. https://doi.org/10.3390/medicines6010003.

23. Gaston TE, Bebin EM, Cutter GR, Liu Y, Szaflarski JP, UAB CBD Program. Interactions between cannabidiol and commonly used antiepileptic drugs. Epilepsia. 2017;58(9):1586-92.

24. Tan G, Jensen MP, Thornby JI, Shanti BF. Validation of the Brief Pain Inventory for chronic nonmalignant pain. J Pain. 2004;5(2):133-7.

25. Lovibond PF, Lovibond SH. The structure of negative emotional states: comparison of the Depression Anxiety Stress Scales (DASS) with the Beck Depression and Anxiety Inventories. Behav Res Ther. 1995;33(3):335-43.

26. Bastien $\mathrm{CH}$, Vallières $\mathrm{A}$, Morin $\mathrm{CM}$. Validation of the Insomnia Severity Index as an outcome measure for insomnia research. Sleep Med. 2001;2(4): 297-307.

27. Guidance for Industry. Food-effect bioavailibility and fed bioequivalence studies. CDER, US FDA; 2002. http://www.fda.gov/downloads/Drugs/Guid anceComplianceRegulatoryInformation/Guidance/ ucm070241.pdf.
28. Galettis P. Development of a simple LCMSMS method for THC and metabolites in plasma. Asia Pac J Clin Oncol. 2016;12(S6):S24.

29. Zhang Y, Huo M, Zhou J, Xie S. PKSolver: an add-in program for pharmacokinetic and pharmacodynamic data analysis in Microsoft Excel. Comput Methods Programs Biomed. 2010;99(3):306-14. https://doi.org/10.1016/j.cmpb.2010.01.007.

30. Guy GW, Robson PJ. A phase I, open label, four-way crossover study to compare the pharmacokinetic profiles of a single dose of $20 \mathrm{mg}$ of a cannabis based medicine extract (CBME) administered on 3 different areas of the buccal mucosa and to investigate the pharmacokinetics of CBME per oral in healthy male and female volunteers (GWPK0112). J Cannabis Ther. 2004;3(4):79-120.

31. Robson P. Abuse potential and psychoactive effects of $\Delta$-9-tetrahydrocannabinol and cannabidiol oromucosal spray (Sativex), a new cannabinoid medicine. Expert Opin Drug Saf. 2011;10:675-85.

32. Page RL, Allen LA, Kloner RA, et al. Medical marijuana, recreational cannabis, and cardiovascular health: a scientific statement from the American Heart Association. Circulation. 2020;142(10): e131-52.

33. Inglet S, Winter B, Yost SE, et al. Clinical data for the use of cannabis-based treatments: a comprehensive review of the literature. Ann Pharmacother. 2020;2:1060028020930189.

34. MacCallum CA, Russo EB. Practical considerations in medical cannabis administration and dosing. Eur J Intern Med. 2018;1(49):12-9.

35. Leehey MA, Liu Y, Hart F, et al. Safety and tolerability of cannabidiol in Parkinson disease: an open label, dose-escalation study. Cannabis Cannabinoid Res. 2020;5(4):326-36. 